\title{
Questão Social e Política de Assistência Social
}

\section{Desigualdade e diversidade: o fator amazônico no contexto da Política de Assistência Social no Pará}

Inequality and diversity: the Amazon factor in context of social assistance policy in Para

\author{
MARIA CARDOSO NASCIMENTO (1) 1 \\ SANDRA HELENA RIBEIRO CRUZ ${ }^{1}$ \\ REINALDO NOBRE PONTES (1) ${ }^{1}$ \\ ${ }^{1}$ Universidade Federal do Pará (UFPA), Belém, Pará, Brasil.
}

8003

RESUMO - Trata-se da problematização do território a partir do entendimento que ele assume no contexto da discussão no Sistema Único de Assistência Social (SUAS). Tem como objetivo contribuir para o debate sobre os limites da política de Assistência Social orientada pelo discurso da desigualdade/diversidade, acionando-se a percepção de trabalhadoras/es do SUAS, radicados no Estado do Pará. Concluiu-se que a concepção de território elucidada na Política Nacional de Assistência Social (PNAS) não se realizava no cotidiano institucional, mas se verificou a presença da concepção de território nas práticas das equipes técnicas.

Palavras-chave: Diversidade. Território. Assistência Social. Fator Amazônico.

ABSTRACT - This problematization of territory based the understanding that assumes in context of discussion in Unique System of Social Assistance (USSA). It aims to contribute the debate about the limits of Social Assistance policy oriented by the discourse of inequality / diversity, stimulating the perception of USSA workers, located in State of Pará. It was concluded that conception of territory elucidated in National Policy of Social Assistance (NPSA) was not performed in everyday activities institutional but the presence of concept of territory in practices of technical teams was verified.

Keyword: Diversity. Territory. Social Assistance. Amazon Factor. 
A

Assistência Social desde o seu reconhecimento, na Constituição Federal de 1988, como política pública de Seguridade Social, enfrentou a sedição de sucessivos governos à sua regulamentação e implementação, como foi o veto à sua primeira regulação infraconstitucional, a Lei Orgânica de Assistência Social (LOAS), dois anos após sua condição de política pública, em 1990, pelo Presidente Fernando Collor de Melo. A referida lei foi aprovada apenas em 1993 no governo do presidente Itamar Franco. A partir de 2003, essa política ganha apoio e centralidade na ação do governo federal, o qual anuncia uma ruptura com a trajetória neoliberal e uma nova cultura política de superação do subdesenvolvimento, através de um crescimento econômico articulado com a justiça social.

A valorização da política de Assistência Social expressa por sua centralização e expansão no contexto da Seguridade Social (Saúde, Previdência e Assistência Social) resultou na instituição do SUAS, que, em 2005, unificou e ampliou os programas de transferência de renda e implementou outros para o enfrentamento à extrema pobreza, os quais ganharam ampla repercussão nacional e internacional. Tais programas, a exemplo de outras políticas setoriais, tinham como desafio responder reivindicações dos movimentos sociais em defesa das mulheres, negros, pessoa com deficiência, trabalhadores rurais e domésticos, bem como indígenas, remanescentes de quilombolas e o segmento populacional que tem sido identificado pela sigla LGBT, historicamente desconsiderados pelas políticas públicas.

De acordo com a Política Nacional de Assistência Social (PNAS), aprovada em 2004, seus usuários passam a ser:

Cidadãos e grupos que se encontram em situações de vulnerabilidade e riscos, tais como: famílias e indivíduos com perda ou fragilidade de vínculos de afetividade, pertencimento e sociabilidade; ciclos de vida; identidades estigmatizadas em termo étnico, cultural e sexual; desvantagem pessoal resultante de deficiências; exclusão pela pobreza e/ou, no acesso às demais políticas públicas [...]" (BRASIL, 2004, p. 27, grifo nosso).

Realizam-se conquistas reconhecidas no Art. III da Constituição Federal de 1988, que afirma "promover o bem de todos, sem preconceito de origem, raça, sexo, cor, idade e quaisquer outras formas de discriminação" (BRASIL, 2008, p.3). Pela citação exposta, esses usuários/as passam a ser reconhecidos por sua existência marcada por opressões e discriminações, resultantes da luta de classes, das contradições de gênero, etnia, geração e deficiência, o que supõe a proposta de pensar a desigualdade contemplando a diversidade na perspectiva das contradições sociais.

Todavia, alguns autores/as têm chamado atenção para questões de ordem conceitual presentes na Política, as quais não ganham materialidade no cotidiano dos espaços de execução. ${ }^{1}$ Dentre esses conceitos, destaca-se o de território, pensado como lugar em que a vida se reproduz pela espoliação e violência das relações sociais, mas também pela criação e resistência culturais dos que experimentam situações de exploração e opressão, numa tentativa de reverter orientações tradicionais que, além de desconsiderarem as condições precárias de infraestrutura e falta de acesso a políticas públicas, ignoravam o cotidiano dos destinatários da Assistência Social (KOGA, 2013).

Interessa neste artigo a tematização do território a partir da realidade Amazônica, mais especificamente, a experiência paraense, ressaltando a percepção de trabalhadoras/es do SUAS radicados no Estado do Pará. Principalmente, àqueles/as que trabalham nas áreas rurais, habitadas por famílias de trabalhadoras/es, que moram à beira dos rios em áreas alagadas ou alagáveis, chamadas populações ribeirinhas, indígenas e quilombolas.

A reflexão do território, expressa pelas/es referidas/es trabalhadoras/es remete a discussão sobre o fator amazônico e aparece como um dos resultados da pesquisa Avaliando a Implementação do Sistema Único de Assistência Social na Região Norte e Nordeste: significado do SUAS para o enfrentamento à pobreza nas regiões mais pobres do Brasil. Nesse sentido, o texto tem como objetivo contribuir para o debate sobre os limites da política de Assistência Social orientada pelo discurso da desigualdade/diversidade, desenvolvida no período de 2003 a 2015 para a Amazônia. 
Organizado em três partes, onde a primeira concentra a análise sobre o debate entre Diversidade e Política Social, objetivando expor a complexidade que recobre esta relação. A segunda, intitulada $O$ Território Paraense na Amazônia, chama atenção para o lugar do estado no bojo da divisão regional, nacional e internacional do trabalho. A terceira, denominada Percepção das/os Trabalhadoras/es e Gestoras/es do SUAS sobre o Território no Pará, expõe dados empíricos que remetem à critica sobre a desconsideração do fator amazônico por falta de condições materiais e percepções governamentais que desconsideram a realidade local.

\section{Diversidade e política social: notas sobre o debate atual}

Inicialmente ressalta-se que não é intenção deste artigo o aprofundamento teórico do conceito diversidade. Todavia, se utilizará da produção de alguns autores/as que têm acumulado historicamente estudos e pesquisas sobre diversidade e desigualdade, particularmente no interior da política social, para subsidiar a análise dos processos de desigualdades produzidos na Amazônia e, reiterados pelas políticas públicas, especialmente a Política de Assistência de Social.

O debate sobre a diversidade quase sempre aparece datada nas décadas de 1960 e 1970 devido à visibilidade ${ }^{2}$ alcançada pelos movimentos feministas, homossexuais, negros, entre outros. Porém, a busca pela valorização das singularidades que cada indivíduo traz acompanha a história da humanidade, por um motivo óbvio: a diversidade está presente em todo agrupamento vivo, seja ele animal, seja vegetal e humano. Portanto, a diversidade é real, concreta, e a tradição marxista dialética nos ensina que o real, a matéria, tem autonomia em relação ao pensamento, à consciência que se elabora deles na clássica premissa: "Não é a consciência que determina a vida, mas a vida que determina a consciência" (MARX; ENGELS, 2007, p. 94).

A autonomia do real em relação à consciência imediata implica em mediações que só são perceptíveis no âmbito da reflexão crítica. Assim, embora a diversidade, entendida como constituinte da individualidade humana (SANTOS, 2008) seja ontológica, sua valorização está condicionado à sociabilidade determinada pelas estruturas econômicas, em particular, pelas sociedades estruturadas pela propriedade privada. Salienta a referida autora que "Pela diversidade, os indivíduos revelam singularidade, apresentam diferenças em seu modo de ser, de se apropriar, de se adaptar ou de buscar transformar as relações vigentes" (SANTOS, 2008, p. 76).

Todavia, "a efetivação da diversidade humana implica na vigência de um projeto societário fundado na igualdade substantiva e não na lógica da diferença e na igualdade de oportunidade que tendem à fragmentação e à formação dos grupos específicos" (SANTOS, 2008, p. 78),

A teoria crítica marxista nos ensina e a prática cotidiana traduz que o mundo do capital inviabiliza tudo que não gera valor de troca. Para que isso ocorra, os seres humanos precisam ser padronizados desde o nascimento. Para o capitalismo, esta padronização caracteriza o social.

Se a lógica da estrutura econômica é gerar riqueza para acumular e não para valorizar a vida, os indivíduos que insurgem da padronização são postos em confrontos com os submissos, gerando fragmentação nas relações sociais, manipuladas pelo sistema como meros conflitos interpessoais entre os mais e os menos aptos a viver em sociedade. A socialização feita desta forma camufla as contradições e os antagonismos, inerentes à sociedade dividida em classes, raça/etnia e sexo. Não obstante, o confronto só é possível porque a dimensão racional do homem, ao mesmo tempo que leva a resignação, permite a sedição, isto é, resistência às opressões e explorações, ora de forma explicita, ora implícita.

Na socialização positivista, que orienta para ordem e a obediência, não há espaço para a vivência, sem tensão, da diversidade pensada como singularidade que cada indivíduo apresenta. Por isso, o capital atento para a capacidade criativa do homem tanto para criar valor de troca, como valor de uso, cria mecanismos capturadores da subjetividade singular, cuja maior expressão é a ideologia ou os aparelhos ideológicos da burguesia, tão eficientes no Brasil do presente.

Segundo Coutinho (1974), é recorrente nos períodos caracterizados como as crises de dominação burguesa, identificados por Georg Lukács como decadência, a reedição de ideologias necessárias à distopia, ou seja, quando a fantasia toma o lugar da realidade. 
Quando atravessa momentos de crise, a burguesia acentua ideologicamente o momento de irracionalista, subjetivista; quando enfrenta períodos de estabilidade, "segurança", prestigia as orientações fundadas num "racionalismo" formal (COUTINHO, 1974, p. 3). "A filosofia da decadência é inteiramente ideológica ocasionando empobrecimento das categorias racionais que operam como práxis manipulatória" (COUTINHO, 1974, p. 4).

Temos assistidos, nos últimos vinte anos, em algumas áreas das ciências sociais, a manipulação de categorias e termos caros à tradição crítica, como: democracia, desenvolvimento, cidadania, liberdade, controle social, sociedade civil, direitos humanos, igualdade, solidariedade e diversidade. Aliás, existe um movimento hoje que defende o retorno à ditadura militar, intitulado Movimento Brasil Livre ou simplesmente MBL.

O tratamento dado à diversidade pela negação das determinações de classe, sexo, raça/etnia e outras injunções não estruturantes, como a geração, a condição física e a regionalidade, tem identificado a diversidade como especificidade de grupos analisados em si mesmos, tendendo a reforçar um individualismo exacerbado de negação da sociabilidade humana. Este individualismo ganha expressão no discurso da igualdade de oportunidade, ou seja, um pouco de esforço próprio e uma "sensibilidade" do capital para quem não se reporta as determinações estruturais, resolve a questão do não acesso ao direito, principalmente ao direito mercantilizado. É o pseudo-humanismo.

Esta é a perspectiva (ideologia) de diversidade que temos assistido nas últimas décadas. Diversidade que é também identificada como multiculturalismo, operado por uma noção de cultura a-histórica e despolitizada, sobretudo, quando a identificação remete a negros, indígenas e pessoas que residem em regiões como a Amazônia que, a despeito da espoliação do trabalho, da terra, da água, em fim da vida nativa, resistem.

Não raro, a sedição aos processos de aculturação, colonização é concebido como exótico! A diversidade, assim entendida, tende a naturalizar a desigualdade inerente à singularidade pensada na totalidade social capitalista. A valorização/efetivação da diversidade no contexto das relações sociais desiguais só é possível pela concessão, pela tolerância ao diferente, o que é muito pouco.

A despeito de carência que se observa hoje de análises estruturais para a compreensão do Brasil contemporâneo em algumas áreas das ciências sociais, a injunção estrutural expressa pelo econômico é onipresente na bibliografia de legado marxista relativa à política social, utilizada principalmente pelo Serviço Social, (BEHRING, BOSCHETTI, 2008; PEREIRA, 2009), postura que concordamos totalmente. Pensar a intervenção do Estado apartado das relações sociais, fundadas pela luta entre classe burguesa e classe trabalhadora é desconsiderar o mundo real, o mundo da vida.

Ao mesmo tempo, cabe reconhecer que, parte desta bibliografia desconsiderou, na análise da política social, outras determinações relevantes da existência humana, que configuram a diversidade no contexto das desigualdades. Uma ilustração desta desconsideração reside no debate dicotômico entre focalização e universalização das políticas sociais brasileiras, perdendo de vista as possibilidades e os limites da concretude dos direitos no horizonte do capital, principalmente quando se sabe que o Brasil é um dos países mais desiguais do mundo.

Castro (2004, p. 281), que defende a perspectiva de que a alquimia raça, gênero, geração tem potencialidade de colaborar na subversão cultural da luta de classes, advoga que:

No debate sobre direitos e políticas para identidades é comum revisitar-se a polêmica entre políticas universais e políticas focalizadas. A meu juízo, forma estéril de se discutir a modelagem de políticas. Se as políticas fossem universais, contemplariam todos e todas, suas necessidades, então seriam universais-e-focalizadas, dialeticamente. [..] 0 desafio maior é como ao mesmo tempo combater uma e todas as iniquidades sociais, combinando portanto políticas focalizadas e universais, fazendo o nexo entre distintos movimentos sociais e não perdendo a perspectiva político-crítica sobre a sociedade estruturada em classes sociais (CASTRO, 2004, p. 281).

O debate das "políticas de diversidade" (SANTOS, 2008) e das "políticas públicas de diversidade, de identidade e/ou de ações afirmativas na classe" (CASTRO, 2004) encontra interlocução com a discussão 
dos "direitos étnicos" (ALMEIDA, 2005), reconhecido no Art. 68, da Constituição Federal de 1988, como nova modalidade de apropriação formal de terras para quilombolas baseada no direito à propriedade definitiva e não mais disciplinada pela tutela, como acontecia com os povos indígenas. Mas, para Almeida (2004), tais direitos se diluem numa perspectiva de política social apartada da categoria de política pública, instrumentalizada pelos tecnocratas neoliberais visando garantir uma divisão do trabalho arbitrária e negando a defesa do universalismo.

Assim, para o referido autor, o foco da política social, que remete ao pertencimento étnico, faz-se sob a égide de outras políticas governamentais, tais como a agrária e as de educação, saúde, habitação e segurança alimentar, ignorando a história e linguagem próprias, bem como o direito à diversidade cultural e religiosa de indígenas e quilombolas, expressões da variedade da cultura humana.

A ampliação do debate sobre diversidade no contexto da discussão acerca das desigualdades tem contribuído para romper com os esquemas teóricos defendidos na academia, marcados por uma racionalidade que tende a reafirmar um conhecimento, reproduzi-lo, e não superar as desigualdades sociais negando a diversidade como constituinte da individualidade humana. Tal processo, contudo, vem sofrendo ameaças do atual Estado brasileiro que tem evidenciado posturas que ilustram a infirmação da desigualdade/diversidade, ao tratar com indiferença a desigualdade e ridicularizar comportamentos e pessoas, no geral, não brancas, que subvertem o paradigma conservador reacionário ameaçando as universidades que dialogam com os sujeitos reais.

No âmbito das políticas públicas, uma das primeiras decisões do Presidente eleito em 2018, foi extinguir a Secretaria de Educação Continuada, Alfabetização, Diversidade e Inclusão (SECADI), seguida da Secretaria Nacional de Políticas para Mulheres (SNPM), substituída pelo Ministério da Mulher, da Família e dos Direitos Humanos, que também se propõe atender algumas demandas, da também extinta, Secretaria de Promoção da Igualdade Racial (SEPIR). Mais recentemente, foram suprimidos os Conselhos de Direitos, iniciando pelo Conselho de Pessoas com Deficiências (PCD). Enfim, assiste-se no Brasil, uma derrocada total nas frentes institucionais da Mulher, Raça/Etnia, Deficiência, GLBT dentre outras.

\section{O Território Paraense na Amazônia ${ }^{3}$}

Como afirmado alhures a categoria território consiste em uma das inovações do SUAS no reconhecimento do protagonismo dos usuários da política de Assistência Social, conforme atesta o parágrafo primeiro da Lei 12.435/2011, que aprimora a LOAS e define com clareza o SUAS "As ações ofertadas no âmbito do SUAS tem por objetivo a proteção à família, à maternidade, à infância, à adolescência e à velhice e, como base de organização, o território" (BRASIL, 2011, p. 1).

O território é concebido como lugar em que a vida se reproduz pela espoliação e violência das relações sociais, mas também pela criação e resistência culturais dos que experimentam situações de exploração e opressão numa tentativa de reverter orientações tradicionais, que desconsideravam o cotidiano dos destinatários da Assistência Social. O território foi apropriado pela primeira vez nas políticas públicas, pelo Sistema Único de Saúde (SUS), implantado em 1990. Ele foi absorvido pela contribuição de Santos, (2002) à desobediência epistemológica da geografia tradicional, centrada no espaço e entendida como lugar físico despolitizado.

Na Amazônia, o território, no interior das discussões sobre a materialização do SUAS, tem sido identificado como fator amazônico, expressão que nas palavras de Teixeira (2013), embora remeta à dívida social que o Estado brasileiro tem com a região, precisa ser ressignificada. Isso porque, uma vez que datada nas décadas de 1970/1980, no contexto da ditadura militar, objetivava enfatizar apenas os aspectos que dificultavam a integração da Região ao Sudeste do País, isto é, suas longas distâncias, seu clima quente e úmido, as chuvas torrenciais e seus insetos.

Ora, essa visão de então não se aproximava nem um pouco da necessária compreensão da particularidade regional, que, no que diz respeito à interface com o SUAS, deve combinar a generalidade das expressões da "questão social" do país, com a singularidade própria deste vasto território (TEIXEIRA, 2013, p. 189). 
A questão que a autora levanta relativa à regionalidade ou a desigualdade regional e a tentativa de depreciar os amazônidas tem sido recorrente na bibliografia local sobre o lugar que a região ocupa na divisão internacional e nacional da produção de riqueza e pobreza. Neste sentido, autores como Costa (1998), Hébette e Castro (2001) dentre outros, têm destacado a incorporação da Amazônia na divisão capitalista global, fornecendo commodities agropecuários, minerometalúrgicos e energéticos ao mercado mundial, levando Castro afirmar "O local está irremediavelmente ligado, nas relações econômicas, ao global, ainda que por processos diferenciados" (CASTRO, 2001, p. 9).

O Pará possui 144 municípios, é o segundo maior território geográfico brasileiro, com área de 1.247.689,5 km² e está dividido, de acordo com a divisão regional do Instituto Brasileiro de Geografia e Estatística (IBGE), em seis Mesorregiões Regiões de Integração (RI). ${ }^{4} \mathrm{O}$ contexto econômico e social do Pará está profundamente ligado à inserção da Amazônia na dinâmica capitalista global, na qual o Estado ocupa, desde os anos 1970, uma posição estratégica.

Os investimentos privados previstos para o território paraense, no período de 2015 a 2020, concentramse, principalmente, nas regiões do Xingu, Grande Belém, Carajás e Tapajós. A previsão é de 173 bilhões de reais em investimentos, considerando, sobretudo, setores como: energia, mineração, infraestrutura e logística, agronegócios, indústria em geral, além de petróleo e gás (SILVA; LIMA, 2017).

As regiões mencionadas alojam projetos econômicos agropecuários, minerometalúrgicos e energéticos, com destaque para a exploração de bauxita pela Companhia Vale do Rio Doce em Parauapebas e a exploração de minério de ferro pelo Programa Grande Carajás, compreendendo o complexo mina-ferrovia-porto e a produção de alumina e alumínio pelo Projeto Albras-Alunorte, em Vila do Conde, no município de Barcarena.

Atualmente, registra-se o complexo de barragens Tapajós e a construção de três hidrelétricas, com destaque para Belo Monte, no Rio Xingu, considerada mais importante do que Tucuruí, concluída na década de 1980, para prover a energia necessária ao abastecimento do Polo Industrial de Barcarena, que com a sua implantação e a da hidrelétrica de Belo Monte, reiteram a tradição: são realizadas mediante intervenção e concessão de subsídio estadual.

Observa-se com isso, a condição de exportador de commodities agudiza-se no presente do estado, reproduzindo a velha lógica de que quem decide a Amazônia e o Pará é o outro, o exterior, ou seja, as empresas minerais, madeireiras, energética, enfim, o capital. Desta forma, a tecnocracia a serviço da desigualdade capitalista não pensa a Amazônia, mas na Amazônia, no Pará, a partir da exploração da terra, da água, da destruição ambiental, do racismo. Os interesses internos, todavia, têm sido defendidos por lutas e movimentos sociais, como o Movimento Xingu Vivo, que tem mobilizado segmentos nacionais e internacionais de resistência na denúncia contra os impactos destrutivos das hidrelétricas nos seres vivos que habitam o Pará rural com expressiva concentração das chamadas populações tradicionais.

Embora indígenas e quilombolas estejam presentes em vários estados do Brasil, o Pará possui a segunda maior concentração de terras indígenas, pois conta com 54 etnias distribuídas em nove das 12 Regiões de Integração do estado. Em 2010, a população indígena era de 51 mil habitantes. Ao que diz respeito aos quilombolas, em 2009 havia cerca de 320 comunidades remanescentes de quilombos, sendo a população estimada em 54 mil pessoas (UFPA, 2015, p. 6). Por outro lado, há um número não informado de ribeirinhos. Todos com demandas gerais e específicas por políticas públicas.

\section{Percepção das/os trabalhadoras/es do Sistema Único de Assistência Social (SUAS) sobre o território no Pará}

O projeto Avaliando a Implementação do Sistema Único de Assistência Social na Região Norte e Nordeste; significado do SUAS para o enfrentamento à pobreza nas regiões mais pobres do Brasil foi orientado por duas dimensões: análise crítica do conteúdo, dos fundamentos e da percepção que os sujeitos diretamente envolvidos na implementação do SUAS têm sobre a Política Nacional de Assistência Social e o SUAS e a investigação sobre a implementação do SUAS em uma amostra intencional das Regiões Nordeste e Norte do Brasil, constituída pelos estados do Maranhão, Ceará e Pará, incluindo uma amostra representativa 
dos municípios destes três estados. Foram selecionados como equipamentos para realização da pesquisa empírica os Centros de Referências de Assistência Social (CRAS), os Centros de Referência Especializados de Assistência Social (CREAS) e os Centros POP - Centro de Referência Especializado para a População em Situação de Rua.

O espaço geográfico para realização do trabalho de campo no Estado do Pará, seguindo critérios e orientações definidas no projeto de pesquisa, foi composto de uma amostra de 06 municípios, tendo como critérios gerais para a seleção, o porte de cada um: a capital do Estado; 01 município de porte grande; 01 município de porte médio; 02 municípios de porte pequeno nível 01 e 01 município de porte pequeno nível $02^{5}$ e o nível de gestão básica ou plena. No Pará, foram selecionados os seguintes municípios: Metrópole: Belém; Grande Porte: Abaetetuba; Médio Porte: Breves; Pequeno Porte Nível I: Inhangapi; e Pequeno Porte Nível II: Salinópolis e Vitória do Xingu. Todos habitados por populações ribeirinhas. Agregam-se a esses, quatro municípios com presença de indígenas e quilombolas.

A pesquisa de campo realizada nos seis municípios paraenses, com a participação de secretárias municipais de Assistência Social e secretário estadual; técnico(a)s, conselheiro(a)s e usuário(a)s sobre a Política de Assistência Social e sobre o SUAS, permitiu inferir similitudes e diferenças na forma de perceber o objeto de investigação. Em relação às semelhanças foi recorrente a relevância dada ao fator amazônico.

Antes de adentrarmos especificamente sobre a mencionada questão, cabe expor uma caracterização breve da Política de Assistência Social, a partir dos dados levantados na investigação. Durante a realização da pesquisa, a Política de Assistência Social no Pará estava presente em todos os municípios. Sendo 42 classificados como de pequeno porte I, 62 de pequeno porte II, 28 de porte médio, 11 de porte grande e 01 metrópole ${ }^{6}$ (PARÁ, 2012). Os 144 municípios executavam a Política de Assistência Social pela descentralização financeira, recebendo os recursos de acordo com o modelo de gestão municipal.

A maioria dos municípios de pequeno e médio porte se encontrava no nível de gestão básico, o que demonstrava a fragilidade da Política no Estado do Pará, principalmente no que tange à capacidade de gestão, tanto da esfera administrativa do estado, quanto dos municípios, merecendo maior atenção das esferas de poder em âmbito federal, estadual e municipal. Aliás, a observação nos espaços de materialização da Política de Assistência Social e os relatos de alguns técnicos e gestores, deixaram claro que inexistia, na maioria dos seis municípios investigados, comprometimento dos prefeitos para melhorar a gestão da Política.

No contexto regional, o Pará possuía a maior concentração de CRAS, totalizando $40,52 \%$ dos equipamentos existentes na Região Norte, abrangendo $46,8 \%$ da concentração populacional. Desta, 53,6\% se encontravam abaixo da linha da pobreza, justificando essa concentração dos CRAS da Região Norte no Estado do Pará.

Outro aspecto importante a ser destacado, diz respeito à localização dos CRAS no Pará, onde 91,6\% estavam em áreas urbanas, destes $59,2 \%$ se encontram em territórios urbanos considerados periféricos, conforme as orientações do SUAS quando se refere ao território (BRASIL, PNAS, 2004). A existência de apenas $8,4 \%$ dos CRAS, mantido pelo governo estadual, em áreas rurais, eram insuficientes, apontando um problema para um estado em que a área rural é responsável pela concentração de grandes contingentes de população tradicional conforme já sinalizado. Na época, o estado totalizava 250 CRAS, representando um crescimento de 59,24\% na implantação deste equipamento num intervalo de sete anos, de 2008 a 2015 (PARÁ, 2016).

Desses CRAS, 243 possuíam cofinanciamento federal e apenas 07 contavam com recurso municipal. As equipes volantes cofinanciadas somaram 85 em 70 municípios e o número de lanchas da assistência ${ }^{7}$ abrangeu trinta e seis (36) municípios ribeirinhos. A partir de outubro de 2013, o governo estadual passou a cofinanciar a Proteção Social Básica e a Proteção Social Especial (de alta e média complexidade), ou seja, os dois níveis de atenção da Política.

O quantitativo dos CREAS no Pará era de 106 unidades, para 144 municípios. Embora considerado um número ainda insuficiente para atender as demandas da proteção social de média complexidade, esse era o maior quantitativo dentre os estados da região Amazônica. Verificou-se que, no período de 2008 a 2015 , houve um aumento de $34 \%$ do número de CREAS no estado, em média $5 \%$ ao ano, a maioria mantida somente com recurso estadual e 02 (dois) na região de integração do Marajó (municípios de Soure e Breves), cofinanciados pelo Governo Federal. 
Em relação ao atendimento da População em Situação de Rua, através de Centros Especializados (Centros Pop), o estado registrava o cofinanciamento de 06 (seis) unidades, com 02 ofertados em Belém, contemplando 05 (cinco) municípios e capacidade de atendimento referenciado para 700 pessoas. As observações e dados coletados no Centro Pop de Belém indicavam uma cobertura bem abaixo do planejado, ou seja, existia nas unidades menos de 100 usuários.

Além desses, o estado ofertava 01 Casa - Dia destinada às pessoas com deficiência, em funcionamento na capital do estado. Ademais, município como Vitória do Xingu, que triplicou sua população em decorrência da hidroelétrica de Belo Monte e vivia a exacerbação de emigrantes, não dispunha de Centro Pop, reivindicação recorrente nos relatos de trabalhadoras/es e conselheiras/os entrevistados.

A existência de CRAS nos municípios e a cobertura parcial de CREAS no Pará não significava efetividade da Política de Assistência, haja vista que o número de CRAS existentes na Região Metropolitana de Belém (RMB). O município melhor equipado, estava aquém da necessidade da população considerada usuária da Política de Assistência Social. Segundo o Diagnóstico Socioterritorial do Município de Belém (BELÉM, 2015), considerando a existência, pelo IBGE 2010, de 143.356 famílias em condições de vulnerabilidade social, a capital paraense necessitaria de 29 CRAS, havendo necessidade de implantação de mais 17 , considerando somente a área urbana, ampliação que não ocorreu. Ademais, as 38 ilhas que faziam parte da RMB estavam totalmente descobertas, embora apresentassem um expressivo contingente ribeirinho.

A necessidade de ampliação da rede de CRAS é reafirmada ao considerar que dentre 08 (oito) capitais brasileiras com quantitativo aproximado de habitantes, Belém apresentava menor número de CRAS, 12 (doze), abaixo de Teresina - 17 (dezessete), São Luís - 20 (vinte) e Goiânia - 15 (quinze), que possuíam população menor que a cidade, respectivamente 814.230, 1.014.837 e 1.302.001 habitantes.

Com relação aos CREAS, a Política Nacional de Assistência Social (PNAS, 2004) estabelece que, para cada 200.000 habitantes, deveria ser implantado um CREAS no município. Belém, segundo estimativa do IBGE para 2015, contava com aproximadamente 1.432.844 habitantes, indicando a necessidade de oferta de mais 07 (sete) equipamentos.

A defasagem entre oferta e demanda dos equipamentos de materialização dos serviços socioassistenciais (CRAS, CREAS, Centros Pop) foi alvo de crítica durante a realização dos grupos focais com técnicas/os e conselheiras/os. Para as/os interlocutoras/es, o critério utilizado pelo SUAS, na definição da oferta dos equipamentos - número de habitantes - desconsiderava a extensão da desigualdade social e, por conseguinte, suas implicações na atualidade em regiões como a Amazônia. A crítica ao reduzido número de equipamentos no Pará remete a outro aspecto do pensamento equivocado dos formuladores das políticas públicas para a região, destacado acima, o qual diz respeito a ideia idílica, harmoniosa, do território e das relações sociais.

No contexto dos municípios pesquisados, observa-se que, de modo geral, a maioria dos CRAS ofertava os serviços definidos pela Política Nacional, como Serviço de Proteção e Atenção Integral às Famílias (PAIF), Serviço de Convivência e Fortalecimento de Vínculos (SCFV), Acolhimento de Crianças e Adolescentes, Medidas Socioeducativas, CADÚNICO, Benefício de Prestação Continuada (BPC), Bolsa Família e os benefícios eventuais, esses últimos sem regulamentação.

O debate realizado no grupo focal com técnicas/os e conselheiras/os, principalmente de Belém e Abaetetuba, indicou profissionais bem informados em relação aos preceitos teórico, técnico e, sobretudo, ideológico da Política. Embora desanimados com a conjuntura e os limites estruturais, reiteraram uma percepção positiva da Assistência Social, adquirida com a implantação do SUAS, principalmente por ter possibilitado, na visão delas/es, qualificação da gestão. A unanimidade da percepção negativada da Política pelas/os informantes referiu-se ao fator amazônico. Passamos então a examinar as avaliações.

Um destaque relevante teve como referência o fato de que a incorporação do fator amazônico na agenda da Política de Assistência Social foi uma conquista das/os trabalhadoras/es amazônidas, organizados em defesa da Política. Assim destacam alguns relatos:

"O tema fator amazônico foi debatido de forma mais recente no Encontro de Gestores Municipais da Região Norte nos dias dezenove e vinte de março de 2013, mas ele é uma luta antiga que temos levantado sobre que a pobreza aqui existe e ela tem 
causas econômicas e de preconceito com a cultura cabocla, indígena e quilombola. Nós daqui da Amazônia, defendemos o fator amazônico assim, mas ele aparece apenas no discurso dos gestores de Brasília." (Interlocução verbal) ${ }^{8}$

“A particularidade da Amazônia nas políticas públicas como na Assistência Social é produto de nossas lutas para ser reconhecidos não só pela pobreza que afeta a maioria dos brasileiros, mas também pela exclusão que sofremos por ter uma cultura própria. Senão nem na lei nós éramos consideramos, porque é isto que significa o fator amazônico no SUAS uma pauta legal sem efetivação real." (Interlocução verbal) ${ }^{9}$

Na percepção das/os conselheiras/os de Belém, Breves e, principalmente, Abaetetuba, o grande dilema da Política Nacional de Assistência Social ocorre na região Amazônica. Nela, fica claro o hiato entre o legal e o real. Como exemplo evidenciado, cita-se as concepções distintas entre técnicos do MDS e técnicos da Região, estes últimos, reivindicando a materialização do que consta na lei, como ilustra o relato a seguir:

\begin{abstract}
“Em um momento eu fiz a interrogação para o técnico do Ministério se o CRAS Quilombola era itinerante e soube que o MDS não reconhece como tal. Eu digo: mas dadas as características? E ele colocou: não, não reconhece como itinerante. Não reconhece e não cofinancia. Então nós não temos equipe itinerante cofinanciada pelo MDS, porque ele não reconhece a nossa realidade mesmo com o fator amazônico. Então a partir do momento quando a colega assumiu a Secretaria, e aí eu tô falando como técnica da Assistência que sou e conhecedora de sua história, é que quando nós íamos para encontros com o MDS, essa era a nossa grande luta de sermos reconhecidos como município diferente, porque somos diferentes. Dentro da região Amazônica tem diversas realidades que a gente tem certa dificuldade que o MDS saia do gabinete venha para cá reconhecer a nossa realidade pra poder escrever política pública para a nossa região, mas infelizmente nós já temos uma política padrão, o Brasil inteiro, pelo menos nós já temos, mas nós queremos muito mais do que é isso, nós queremos ser reconhecidos também como uma realidade presente dentro do território brasileiro e que precisa ser enxergada como tal a luta foi grande. Conseguimos já em 2013, na NOB SUAS ser reconhecido como fator amazônico, se não me engano no artigo 62 da NOB SUAS aprovada em 2013, mas não é só isso, não é só ser reconhecido. O reconhecimento não foi fácil, mas já foi. Hoje nós queremos o cofinanciamento diferenciado, porque nós precisamos disso. Hoje nós somos reconhecidos, tudo bem, ótimo, mas isso ficou no papel e isso não pode ser letra morta. Então, tem que ser além do que tá escrito." (Interlocução verbal) ${ }^{10}$
\end{abstract}

Outros relatos se fizeram na direção à crítica da ausência de cofinanciamento para viabilização do fator amazônico:

“[...] Tem uma lancha que foi dada pelo MDS, mandada, muito linda, mas ela não atende a minha demanda. A equipe volante tem que chegar até comunidades mais distantes, mas necessita mesmo daquele atendimento. Com a lancha que o MDS mandou eu não consigo realizar esse atendimento, pra mim chegar a uma extremidade do município de Breves eu demoro aí quase um dia pra chegar, se não um dia e meio, mas com a lancha que eu utilizo no momento. Ela não tem como montar rede, ela não tem como fazer, digamos, uma estadia nesse meio de transporte. Ou seja, quando eu tenho que me deslocar pra algum desses lugares eu preciso de uma lancha alugada sendo que nós temos uma lancha." (Interlocução verbal) ${ }^{11}$

"Temos uma população ribeirinha significativa em Cotijuba, uma ilha que fica aqui em Belém, nem lá é possível afirmar que o fator amazônico se concretiza, pois temos uma lancha, mas não temos dinheiro para o combustível e outras manutenções do veículo. Isto implica na não garantia do acesso a Política." (Interlocução verbal) ${ }^{12}$ 


\begin{abstract}
“[...] A questão da necessidade de uma equipe volante. Não há cofinanciamento da equipe volante e vocês veem na fala da técnica de CRAS a necessidade de uma equipe volante. O município já custeou a equipe volante até pra ajudar nas ações de CRAS, mas aí essa situação de crise, mais arrecadação, teve que haver um ajuste na folha e infelizmente nós perdemos a nossa equipe volante por conta até de atraso para repasse de recurso vem atrapalhando muito a ação da assistência." (Interlocução verbal) ${ }^{13}$
\end{abstract}

Os relatos acima deixam evidente o descaso com o art. 62 da Resolução no 33/2012, que reconhece: "[...] o co-financiamento dos serviços socioassistenciais de proteção social básica e especial deverá considerar fatores que elevam o custo dos serviços na Região Amazônica [...]" (BRASIL, 2012, p. 21). Ou seja, parece que o fator amazônico se apresenta como forma legal daquilo que não pode ter forma legal.

A não materialização da singularidade da Assistência Social, na particularidade Amazônica, é ilustrada pelas/os informantes por meio do tratamento dado aos usuários, em especial, das populações tradicionais da área rural conforme pode ser observado nos relatos abaixo:

"No caso da população, a criação do SUAS foi o maior avanço que eles poderiam ter do ponto de vista da organização de sua condição de usuário, apesar da inviabilização do fator amazônico que na prática nega o usuário quilombola, indígena e ribeirinho quando não oferece condições de garantia de sua particularidade cultural, geográfica. Não tem técnico, não tem lancha adequada para deslocamento para as ilhas." (Interlocução verbal) ${ }^{14}$

"Eu tô há oito anos trabalhando na Assistência Social. Percebo que o grande mérito da Política de Assistência Social criada a partir de 2003, foi o trato pela tipificação dos serviços. Como eu venho da época do Pro-Jovem, então eu consegui sentir o impacto que foi dado pela tipificação onde você realmente padroniza essas nomenclaturas e você começa e toda a sua equipe desde a gestão à direção, os técnicos que estão na ponta e aí os orientadores de nível médio que estão com esses adolescentes, falando especificamente sobre o Serviço de Convivência e Fortalecimento de Vínculos, então você consolida uma característica para esse serviço, ele tem um nome, ele tem um direcionamento, você não tem mais aquela perspectiva de trabalhar num determinado serviço vinculado à Assistência que eu enxergava muito isso antes, onde há uma pulverização de ideias e um indicativo muito grande senso comum e de achismo: olha eu acho que é melhor a gente trabalhar com essa população dessa forma. Então, há uma padronização. É claro que ela se dá de modo diferenciado em cada território etc, e aqui entra o descaso com o fator Amazônico. Nós por exemplo ganhamos uma lancha que é inadequada para os nossos rios e ninguém resolve a situação." (Interlocução verbal) $)^{15}$

Outra ilustração desta crítica, diz respeito à ausência nos municípios pesquisados de espaço físico de CRAS Quilombola e Indígena. Algumas ações dirigidas para os referidos usuários, por exemplo, as orientações sobre o Programa Bolsa Família e o BPC ocorriam em escolas e centro comunitários das comunidades. Remetendo, com isso, ao fato de que o discurso é do reconhecimento da heterogeneidade, mas a prática é da reprodução da homogeneidade, numa demonstração de que na regulamentação a diversidade pode ser acionada como discurso sem prejuízo da manutenção da desigualdade.

Ainda segundo observações in loco e os relatos das/os trabalhadoras/es do SUAS, a garantia de condições de trabalho condizentes com a realidade local e a adequação das variáveis de registro no sistema SUAS inexistia, como fica evidente na fala abaixo:

"Eu percebo hoje na política municipal de Assistência Social que nós tivemos um grande avanço nas nossas ações, porque quando foi pensada a política de Assistência foi para todo território. Infelizmente, nós ainda não conseguimos isso. Porque a realidade do nosso município é de 72 ilhas. Esse é o nosso grande desafio: chegar até lá porque nós ainda não conseguimos devido a questão de recursos financeiros, porque 
tem que ter uma equipe dedicada para atender só a proteção básica nesses locais, como não tem, a equipe que está no CREAS na região urbana faz este atendimento. A proteção social especial também deveria chegar tanto nas ilhas quando nas regiões de estradas. Então nós participamos de outros encontros em outras regiões do país e com outros municípios e o que a gente percebe é que, apesar das nossas dificuldades e entraves no território municipal, nós estamos à frente de alguns municípios, por conta do entendimento e por conta que a equipe aceita o desafio do compromisso com os que precisam da Assistência fora do urbano. Os profissionais que vêm trabalhar no município não enxergam os entraves geográficos que o município possui como um entrave pessoal para não ir até lá. Eles aceitam o desafio e acabam realizando e elaborando estratégias diferentes do que o MDS pensa." (Interlocução verbal) ${ }^{16}$

Este relato deixa claro que, para as técnicas(os) locais, a adversidade geográfica não se constitui um problema, mas que ela precisa de tratamento distinto e, muitas vezes, tenta concretizá-la por meio de "estratégias diferentes", ou seja, tornando o "impossível" para o institucional, "possível" para a/o gestora/or e para a/o técnica/o. A dificuldade de operacionalizar as ações da Política concernente ao reconhecimento da diversidade no contexto do Pará estava presente não só nos CRAS e CREAS das comunidades dos municípios, mas nas sedes, manifestada na precariedade da infraestrutura e das condições e relações de trabalho.

As/os interlocutoras/es denunciaram que trabalham muito, uma vez que precisam responder às situações de insuficiência de condições administrativas, materiais e humanas como fica explicito neste relato ao criticar a indiferença da burocracia com os endereços das populações tradicionais:

"[...] Outra situação é a falta de reconhecimento dessa realidade que nós temos e de falar no censo SUAS sobre isso, nós não temos nem endereço nós não podemos colocar rio fulano de tal, braço de ilhas, furo, igarapé, nós não podemos colocar isso lá, porque não existe espaço, variável no sistema, mas não é por falta de não dizer que existe, porque existe." (Interlocução verbal) ${ }^{17}$

Em Abaetetuba foram identificados seis CRAS Quilombolas que apareciam também como CRAS rurais, nos cadastros da Secretaria Municipal de Assistência Social do município. Porém, sem espaço físico, utilizando-se provisoriamente como base uma sala de referência na sede da secretaria, uma demonstração do que o relato acima revela como ausência de endereço para o censo SUAS.

Por tudo que foi exposto sobre a implantação do SUAS no Pará fica claro que a abordagem do território era garantida pelo viés espacial na medida em que a maioria dos CRAS estava próxima das residências dos usuários, marcadas por vulnerabilidade social das famílias, uma vez que a violência que avançava no meio rural paraense, colocava em risco a vida das/os usuárias/os e das/os trabalhadoras/es, bem como a destruição dos poucos equipamentos e mobília desses espaços. A exceção foi o CRAS de Inhangapi, localizado no centro da cidade, área comercial, distante da periferia e alvo de críticas por causa da sua localização. A locomoção dos usuários para este equipamento era garantida por transporte municipal que tinha horário específico, implicando perda de acesso quando a/o usuária/o não se encontrava no local na hora estipulada.

Por outro lado, é importante observar que nas falas das técnicas e conselheiras entrevistadas na pesquisa antes mencionadas que há uma compreensão divergente tanto da relevância do fator amazônico quanto de território, que concorda com os avanços expressos na PNAS, quanto a questão da diversidade, e que critica as posições do MDS que contradizem tais avanços. Mais importante que isso são as práticas de resistências - manifestas no discurso e na ação - que implica em incorporar ao cotidiano da ação da Política de Assistência Social que chega aos municípios amazônidas compreensões e práticas mais avançadas, a despeito das ações contraditórias do MDS. É a identificação da dialética da continuidade-descontinuidade contida na realidade. 


\section{Considerações finais}

Este texto se propunha contribuir para o debate sobre os limites da política de Assistência Social orientada pelo discurso da desigualdade/diversidade, desenvolvida nos últimos anos para a Amazônia. Para tanto, tentamos problematizar o debate sobre as políticas sociais no bojo das injunções pautadas na desigualdade econômica e na condição de diversidade, entendida como constituinte da individualidade humana e instrumentalizada como inferioridade ou como exótico, ambas adjetivações construídas pela sociabilidade capitalista para reafirmar desigualdades próprias de sociedades estruturadas pela propriedade privada. A diversidade, por si só, ou entendida a partir dessas adjetivações, não produz autonomia, uma vez que o não reconhecimento da diversidade, um dos fatores determinantes dos direitos acaba por vulnerabilizar toda a eloquência dos direitos fundamentais.

Neste sentido, observou-se que o arcabouço jurídico das políticas sociais estabelecido na Constituição Federal do Brasil de 1988 incorpora as reivindicações dos movimentos sociais por ações governamentais que não desconsiderando as desigualdades decorrentes da divisão de classes, reconhece a existência múltipla de desigualdades, expressas, no geral, por discriminações e opressões em decorrência de sexo, gênero, raça/etnia, idade, região, deficiência etc.

Neste contexto, o destaque foi dado à Política de Assistência Social quando faz uso do território como uma categoria que concebe seus usuários a partir de múltiplas determinações. Esta concepção é identificada para usuárias/os que residem na Amazônia como fator amazônico.

Trabalhadoras/es, gestoras/es e conselheiras/os ouvidos nos municípios pesquisados no Pará indicaram que a concepção de território elucidada na PNAS não se realiza no cotidiano institucional, as condições oferecidas para condução da Política reiteram o território como território. Mas, por outro lado, se identifica no discurso e nas práticas das equipes técnicas (não homogeneamente) a realização da concepção de território, não capitulado ante as imposições estruturais do nível ministerial.

O que não significa solução da contradição, mas a expressão de sua existência, e da resistência na direção do avanço da Política de Assistência Social. Mesmo que o discurso governamental reconheça a particularidade da regionalidade na singularidade da Amazônia brasileira, no bojo da universalidade desigual do Brasil, o cotidiano remete ao "canto da sereia", uma vez que não há condições favoráveis para sua materialização.

Entendemos que não se pode falar de condições parciais de direitos de indígenas, ribeirinhos e quilombolas, uma vez que por si só a inexistência de conteúdos e ações concernentes a seus direitos culturais já seria grave, o que dizer da inexistência de equipamentos em seus locais de moradia ou de vida. Nesse sentido o velho modelo sobrevive: o fator amazônico pensado pela ditadura militar do qual nos fala Teixeira, tensionado pelas forças progressistas que não capitulam.

\section{Referências}

ALMEIDA, A. B. W. Solidariedades ameaçadas e a redefinição do serviço público. In: NEVES, R.H. N. et al. (org.).

A reinvenção do social: poder popular e política de assistência em Belém. Belém: Paka-Tatu, 2004.

ALMEIDA, A. B. W. Nas bordas das políticas étnicas: os quilombos e as Políticas Sociais. Boletim Informativo do Núcleo de Estudos sobre Identidades e Relações Étnicas da Universidade Federal de Santa Catarina, v. 2, n. 2, p. 15-44, 2005.

BEHRING, E. R.; BOSCHETTI, I. C. Políticas Sociais: Fundamentos e História. São Paulo: Cortez, 2008.

BELÉM. Diagnóstico Socioterritorial do Município de Belém. Belém: Prefeitura Municipal de Belém, 2015.

BRASIL. [Constituição (1988)]. Constituição da República Federativa do Brasil. São Paulo: Saraiva, 2008.

BRASIL. Ministério do Desenvolvimento Social e Combate à Fome. Política Nacional de Assistência Social. Brasília, DF: Ministério do Desenvolvimento Social e Combate à Fome, 2004. 
BRASIL. Ministério do Desenvolvimento Social e Combate à Fome. Lei no 12.435, de 6 de julho de 2011. Brasília, DF: Ministério do Desenvolvimento Social e Combate à Fome, 2011. Disponível em: http://www.cfess.org.br/arquivos/ Lei-12435.pdf. Acesso em: 2 ago. 2018.

BRASIL. Conselho Nacional de Assistência Social. Resolução no 33, de 12 de dezembro de 2012: aprova a Norma Operacional Básica do Sistema Único de Assistência Social. Brasília, DF: Conselho Nacional de Assistência Social, 2012. Disponível em: http://www.mds.gov.br/cnas/noticias/publicada-hoje-a-nova-norma-operacional-basica-nob-suas-2012. Acesso em: 2 ago. 2018.

CASTRO. E. M. R. Estado e Políticas Públicas na Amazônia em face da Globalização e da Integração de Mercados. In: COELHO, M. C. N. et al. (org.). Estado e políticas públicas na Amazônia: gestão do Desenvolvimento Regional. Belém: UFPA: NAEA, 2001, p. 7-32.

CASTRO, M. G. Políticas públicas por identidades e de ações afirmativas: acessando gênero e raça, na classe, focalizando juventudes. In: NOVAES, R.; VANNUCHI, P. (org.). Juventude e sociedade: trabalho, educação, cultura e participação. São Paulo: Fundação Perseu Abramo, 2004, p. 275-302.

COSTA, F. A. Ciência, tecnologia e sociedade na Amazônia: questões para o desenvolvimento sustentável. Belém: UFPA: NAEA, 1998.

COUTINHO, Carlos. Nelson. O estruturalismo e a miséria da razão. Rio de Janeiro: Paz e Terra, 1974.

HÉBETTE. J. Cruzando Fronteiras: 30 anos de estudos do campesinato na Amazônia. Belém: EDUFPA, 2004. v. 1.

KOGA, D. Aproximações sobre o conceito de território e sua relação com a universalidade das políticas sociais. Serviço Social em Revista, Londrina, v. 16, n. 1, p. 30-42, jul./dez. 2013. https://doi.org/10.5433/1679-4842.2013 v16n1p30

MARX, K.; ENGELS, F. A ideologia alemã. São Paulo: Boitempo. 2007.

PARÁ. Fundação Amazônia de Amparo a Estudos e Pesquisas. Anuário de Assistência Social do Estado do Pará. Belém: Fundação Amazônia de Amparo a Estudos e Pesquisas, 2016.

PARÁ. Secretaria do Estado de Assistência. Plano Estadual de Assistência Social 2012-2015. Belém: Secretaria do Estado de Assistência, 2012. Disponível em: http://www.seas.pa.gov.br/seas/plano-estadual-de-assist\%C3\%AAncia-social. Acesso em: 13 out. 2016.

PEREIRA, A. P.. Política Social: temas \& questões. São Paulo: Cortez, 2009.

RODRIGUES, M. P. Balanço Crítico do SUAS e o Trabalho do/a Assistente Social. In: SEMINÁRIO NACIONAL O TRABALHO DO/A ASSISTENTE SOCIAL NO SUAS, 2009, Rio de Janeiro. Anais [...]. Rio de Janeiro: Conselho Federal de Serviço Social, 2009.

ROJAS, B. Por uma política social pública. A luta contra uma assistência social considerada como mero sistema gerencial. Entrevista por João Vitor Santos. Revista IHU, São Leopoldo, 2015. Disponível em: www.ihu.unisinos.br. Acesso em: 2 dez. 2017.

SANTOS, M. A natureza do espaço: técnica e tempo, razão e emoção. São Paulo: Edusp, 2002.

SANTOS, S. M. Direitos, desigualdade e diversidade. In: BOSCHETTI, I.; BEHRING, E. R.; MIOTO, R. C. T.; SANTOS, S. M. (org.). Política social no capitalismo: tendências contemporâneas. São Paulo: Cortez, 2008.

SILVA, Maria Ozanira da Silva e; LIMA, Valéria Ferreira Santos de Almada. Caracterização Socioeconômica das Regiões, Estados e Municípios Espaços Empíricos da Pesquisa. Maranhão: Mimeo, 2017.

TEXEIRA, J. B. A Amazônia e a interface com o SUAS. In: CRUZ, J. F. da et al. 20 anos da Lei Orgânica de Assistência Social. Brasília, DF: MDS, 2013.

UFPA. Instituto de Ciências Sociais Aplicadas. Programa de Pós-Graduação em Serviço Social. Proposta de doutorado. Belém: UFPA, 2015. 


\section{Notas}

${ }^{1}$ Ver análise de Rodrigues (2009) a respeito do trabalho dos assistentes sociais no SUAS e de Teixeira (2013) sobre o fator amazônico no contexto do SUAS. Na mesma direção, pode-se considerar a ponderação de Rojas: "[...] para que a Assistência Social seja efetivamente um direito social, é preciso dar a esse campo uma institucionalidade politizada, com debate sobre acesso, financiamento, enfim, todos os elementos da política" (2017, p. 5, grifo da autora).

2 Uma das expressões desta conjuntura foi o movimento denominado por "Maio 68", que completou em 2018,50 anos.

3 A Amazônia brasileira é também conhecida como Região Norte, de acordo com o conceito definido pela divisão política do Brasil, abrange sete estados, Amapá, Amazonas, Acre, Rondônia, Roraima, Pará e Tocantins e uma área de 3,8 milhões de km2, ou seja, 44\% do Brasil.

${ }^{4}$ Baixo Amazonas, Marajó, Nordeste, Metropolitana de Belém, Sudeste e Sudoeste. O governo do estado do Pará considera 12 Regiões de Integração (RI): Rio Caeté, Baixo Amazonas, Araguaia, Tapajós, Carajás, Guamá, Tocantins, Marajó, Lago de Tucuruí, Rio Capim, Xingu e Metropolitana (SILVA; LIMA, 2017).

${ }^{5}$ Conforme adotado pela Política Nacional de Assistência Social de 2004, são considerados municípios pequenos nível 01 (até 20.000 habitantes); municípios pequenos nível 02 (de 20.001 a 50.00 habitantes); municípios médios (50.001 a 100.000); municípios grandes (entre 100.001 a 900.000 habitantes) e as metrópoles, cidades com população de 900.0000 . O critério a ser considerado na seleção dos municípios dos diferentes portes é o nível de estruturação maior ou menor da Política de Assistência Social nos municípios dos Estados selecionados (BRASIL, 2004).

${ }^{6}$ Segundo definição da Política Nacional de Assistência Social, de 2004, são considerados municípios pequenos nível 01 (até 20.000 habitantes); pequeno nível 02 (de 20.001 a 50.00 habitantes); municípios médios (50.001 a 100.000); municípios grandes (entre 100.001 a 900.000 habitantes) e as metrópoles, cidades com população de 900.0000 (BRASIL, 2004).

7 As lanchas volantes de assistência consistem inovação do SUAS e atendem a uma reivindicação histórica das/os trabalhadoras/es da Política de Assistência Social que residem nos municípios cercados por ilhas e rios.

${ }^{8}$ Secretária de Assistência Social de Abaetetuba. Abaetetuba/Pará, 2016.

9 Retirada do grupo focal com Técnicos e Conselheiros/as de Abaetetuba. Abaetetuba/Pará, 2016.

${ }^{10}$ Retirada do grupo focal com Conselheiras/os do CMAS em Abaetetuba. Abaetetuba/PA,2016.

${ }^{11}$ Retirada da entrevista com a Secretária de Assistência Social de Breves. Breves/PA,2016.

${ }^{12}$ Retirada da entrevista com a Presidente da FUNPAPA. Belém/PA, 2016.

${ }^{13}$ Retirada do grupo focal com Técnicas/os em Abaetetuba. Abaetetuba/PA, 2016.

${ }^{14}$ Retirada do grupo focal com Técnicas/os em Abaetetuba. Abaetetuba/PA, 2016.

${ }^{15}$ Retirada do grupo focal com Técnicas/os em Salinas. Salinas/PA, 2016.

${ }^{16}$ Retirada do grupo focal com Conselheiras/os do CMAS em Abaetetuba. Abaetetuba/PA, 2016.

${ }^{17}$ Retirada do grupo focal com Técnicas/os em Abaetetuba. Abaetetuba/PA, 2016.

Recebido em: 20/09/2018.

Aprovado em: 08/11/2019.

Publicado em: 10/02/2020.

\section{Correspondência para:}

Maria Cardoso Nascimento

Universidade Federal do Pará

Cidade Universitária Prof. José da Silveira Neto

Av. Augusto Corrêa, 01 - Bairro Guamá

66075-110, Belém, PA, Brasil

\section{Autores:}

MARIA CARdoso NASCIMENTO

Assistente Social, graduada pela Universidade Federal do Pará (UFPA), mestrado no Núcleo de Altos Amazônicos (NAEA/UFPA),

doutorado na Pontifícia Universidade Católica de São Paulo (PUC-SP). Professora do Programa de Pós-Graduação em Serviço Social da Universidade Federal do Pará.

Orcid: http://orcid.org/0000-0002-2931-1967

E-mail: mariaant@ufpa.br

SANDRA HELENA RIBEIRO CRUZ

Doutora em Serviço Social. Professora da Faculdade e do Programa de Pós-Graduação em Serviço Social da UFPA.

Orcid: http://orcid.org/0000-0002-9360-5759

E-mail: cruz.sandra761@gmail.com

REINALDO NobRE PONTES

Doutor em Serviço Social. Professor da Faculdade e do Programa de Pós-Graduação em Serviço Social da UFPA.

Orcid: http://orcid.org/0000-0002-1371-450X

E-mail: rnobrepontes@gmail.com 